\title{
Airborne Aspergillus and Penicillium in the atmosphere of Szczecin, (Poland) (2004-2009)
}

\author{
Agnieszka Grinn-Gofroń
}

Received: 18 February 2010/Accepted: 20 July 2010/Published online: 3 August 2010

(C) The Author(s) 2010. This article is published with open access at Springerlink.com

\begin{abstract}
The investigation into airborne fungal spore concentrations was conducted in Szczecin (Poland) between 2004 and 2009. The objective of the studies was to determine a seasonal variation in concentrations of amerospores on the basis of meteorological parameters. The presence of spores in Szczecin was recorded using a volumetric method. Fungal spores were present in the air in high numbers in late summer and early autumn. The highest concentrations were noted in September, October and November. The peak period was recorded in August, September, October and November. The highest annual number of spores occurred in 2005 and 2007 and the lowest in 2006. High values of daily concentration of amerospores occurred during the afternoon and late at night. In 2005 and 2007 the latenight maximum was overdue about 1 or 2 h. For daily values of dew point temperature and relative humidity, the coefficients were positive, significant for $p=$ 0.001 and ranged from 0.342 to 0.258 . The average wind speed was positively correlated for $p=0.01$ and the coefficient was 0.291 . The similar relations were noted for hourly values of spore concentrations for $p=0.05, p=0.01$ and $p=0.001$. For these
\end{abstract}

A. Grinn-Gofroń (ه)

Department of Plant Taxonomy and Phytogeography, University of Szczecin, Wąska 13, 71-415 Szczecin,

Poland

e-mail: agofr@univ.szczecin.pl spore types, the dew point temperature and relative humidity appeared to be the most influential factor.

Keywords Aspergillus/Penicillium - Amerospores · Airborne spore concentrations · Meteorological parameters $\cdot$ Statistical relationships

\section{Introduction}

Fungal spores play a significant role in plant pathology and human respiratory allergy. Their concentration in the atmosphere is the result of complex interaction between biological and environmental factors; however, relatively little is known about these relationships. The individual importance of each parameter is hard to assess due to the dynamic nature of the atmosphere. Such factors include the time of day, geographic location, air pollution, weather conditions, human activity and local sources of vegetation. Knowledge of the relations between spore production and different environmental growth conditions can be used to effect more efficient and reliable application of pesticides, or to improve diagnosis and treatment of respiratory allergic diseases (Rodriquez-Rajo et al. 2005).

The first investigations into airborne fungal spores in Poland were conducted in the two cities: Kraków and Rabka (Weiss 1962) where 15 types of fungal spores were identified. Studies of the concentration of fungal spores performed in Poland thus far refer to 
outdoor analyses (Gaweł et al. 1996; Kasprzyk et al. 2004; Konopińska 2004; Myszkowska et al. 2002; Stępalska et al. 1999; Stępalska and Wołek 2005) as well as indoor analyses (Mędrela-Kuder 1991, 2003).

Amerospores are small, round, non-septate asexual spores or spore-like particles, indistinguishable from each other at $600 \times$ magnification using light microscopy. They mainly include unchained spores of Aspergillus and Penicillium, which are the most numerous in this group. Amerospores can also allow Acremonium, Trichoderma, Verticillium, Paecilomyces, Scytalidium, Cunninghamella, Monocillium, Gliocladium, and some yeasts.

Both taxa Aspergillus and Penicillium are omnipresent saprophytes and dominate in temperate soils, and the spores are easily liberated and dispersed into the air. The genus of Aspergillus consists of 160 species, which are frequently found on plants and plant debris (Gravesen 1979). Members of the Aspergilli can be also isolated from raw textile materials, e.g. cotton, kapok, hemp and jute.

Most species in the filamentous fungi are regarded as difficult to identify and this is particularly pronounced in the genus Penicillium (Samson and Pitt 1990). A frequently cited review on the problem of Penicillium (Onions et al. 1984) anticipated results of a multidisciplinary study to address taxonomic difficulties (Bridge et al. 1989; Paterson et al. 1989). Problems stem from reliance on subtle differences in terverticillate penicillia conidiophores. Identifications are still done by morphology, with a few recent physiological and chemical/molecular methods, despite the fact that many of the non-physiological and chemical features are regarded as subjective. Species level identifications are often very difficult and many errors exist in the literature (Paterson et al. 2004). New varieties and species have been created only to be reclassified as members of existing taxa (Frisvad et al. 2000). Novel techniques have revealed characters, which were previously unreported in some species (Paterson et al. 2003). rDNA sequence analyses demonstrated that the subgenus Penicillium is predominately monophyletic, and current species may be varieties (Peterson 2000). Members of Penicillium are found on stale bread, citrus fruits, legumes and apples. Penicillium associated with rye flour is a problem in industrial bakeries causing aftercontamination of bread (Gravesen 1979).
The spore monitoring, based on volumetric method, was conducted in Szczecin in 6 consecutive years (started from 2004). For statistical analysis of long-term results, more reliable are data from the full period of 6 years that were used in the calculation.

No aerobiological researches of the spore aeroallergen circulation season had been developed in Szczecin before.

The present study was undertaken to assess the seasonal and diurnal variations in one of the ambient airborne fungal spore concentrations in Szczecin. The main objective of the study was to investigate the relationships between fungal spores in the air and meteorological factors using statistical analysis, both for the daily and hourly values.

\section{Materials and methods}

In Szczecin area, the sampler was located at Faculty of Natural Science $\left(53^{\circ} 26^{\prime} 26^{\prime \prime} \mathrm{N}, 14^{\circ} 32^{\prime} 50^{\prime} \mathrm{E}\right.$; height: $21 \mathrm{~m}$ above ground level). Śródmieście district covers the central part of Szczecin. According to the Office of the City of Szczecin from June 24, 2007, the district has a population of 132,868 permanent residents and its urban structure is rather scattered with many green squares and parks. The measuring site was $0.5 \mathrm{~km}$ NW from Jan Kasprowicz Park, the largest green complex in Szczecin on the east bank of the Odra river. This area is characteristic for location of many different species of plants, which mainly include Pinus, Platanus, Betula, Tilia, Fagus, Aesculus and many taxa of the Rosaceae family: trees, shrubs and herbaceous plants. One part of the park is approximately $3 \mathrm{~km}$ from Lanzoni trap, gardens with a large number of fruit trees, which may be one potential source of spores recorded in the air. The second source can be buildings surrounding the platform with spore trap and the same building of the Faculty where the measuring mechanism is located. All buildings are old and come from the prewar period. The conditions indoors are favorable for fungi because of a moist microclimate and the fact that the premises are not maintained and used properly, the aesthetic appearance may be affected by development of mold growth, or mildew on walls, flooring, furniture, etc. Such biodeterioration as well 
as leaky windows and doors also adds to the number of spores in the air out of the building.

The present, "baltic" climate of Szczecin is influenced by impact of the air masses from over the Northern Atlantic and is characterized by mild winters and cool summers. The presence of large aquatic resources, as the Szczecin Lagoon, Miedwie Lake and the Odra river valley, increases the humidity in these areas. The average relative humidity was $80 \%$, the highest $-88 \%$, which occurs in November, December and January, and the lowest about $72 \%$ in April and May. The average air temperature in Szczecin ranges from 8 to $8.4^{\circ} \mathrm{C}$. The warmest month is July with temperatures of $15.8-20.3^{\circ} \mathrm{C}$, the coldest-January from -4.1 to $2.6^{\circ} \mathrm{C}$. Air temperature below $0^{\circ} \mathrm{C}$ occurs on average within 86 days a year, usually in January and February. Average annual rainfall is $537 \mathrm{~mm}$ and within a year there are approximately 167 days with precipitation.

Daily spore concentration was sampled using 7day volumetric spore trap (Lanzoni 2000) with a flow rate of $10 \mathrm{~L} \mathrm{~min}^{-1}$, between 1 January 2004 and 31 December 2009. The spore monitoring was performed during the whole year.

The meteorological data covering 6 years of studies were provided by the Automatic Weather Station (Vaisala MAWS101). The meteorological station was located at a distance of one meter from spore trap on the same platform. The meteorological parameters considered were daily level of precipitation, maximum wind speed, average wind speed, relative humidity, maximum, minimum and average air temperature, temperature of the dew point. The daily values of these parameters were taken as arithmetic means.

Since our intension was to predict hourly patterns of amerospores spore concentrations, it was indispensable to use "hour" as independent variable. Another reason to include time of the day in the analysis was that it was weakly correlated with meteorological parameters-only with temperature and dew point temperature (Spearman's correlation coefficients 0.2-0.4, results not shown). Consequently, this study assumed that "hour" might represent some other unknown factors influencing spore concentrations, not measured or taken into account in the analyses.

The spore data were analyzed to determine the start, the end and the duration of the season using the $90 \%$ method. The start of the season was defined as the date when $5 \%$ of the seasonal cumulative spore count was trapped and the end of the season as the date when $95 \%$ of the seasonal cumulative spore count was reached (British Aerobiology Federation 1995).

Because spores with a length/width ratio $<15$ : 1 and without significant curvature or ornamentation are very similar and unidentifiable by direct microscopic examination for the purpose of this work, they were categorized under one group of amerospores.

Spores were trapped onto a Melinex adhesive tape and cut into daily parts. The daily mean concentration of the number of fungal spores was determined using an optical microscope at a magnification of $\times 400$ along one lengthwise traverses. After the spore counting in each sampling area, a specific correction factor for the used microscope was applied. Thus, the final counts of fungal spores were expressed as average daily number of spores per cubic meter of air. Monthly cumulative totals were calculated for all years and correlated with meteorological data. In order to verify the accuracy of calculations performed under the microscope, most of the samples have been re-viewed using a microscopic camera connected to a computer screen. We realize that we not achieved a perfect accuracy of the results obtained, but we anticipate that our effects are sufficient for the aerobiological analysis.

The statistical relationship between spore concentration and meteorological factors was established using the Statistica program version 6.1 (StatSoft, Inc. 2002). Due to non-linearity and non-normality, neither the Pearson's correlation coefficient nor multiple regression could have been used. Therefore, the Spearman's rank correlation was applied in order to examine the studied relations. Peak daily counts were identified for all years from 2004, and daily slides with the highest spore concentrations were chosen and transverse traverses were counted every hour to observe diurnal variation.

\section{Results}

Amerospores accounted approximately $1 \%$ of all monitored spore types during the 6-years aerobiological monitoring in Szczecin. The list of all examined taxa contained approximately 70 items. The most numerous taxa (with a percentage above $10 \%$ ) were 
Cladosporium, Alternaria, Ganoderma, Didymella, Leptosphaeria, Drechslera, Pleospora, Torula, Epicoccum and Pleospora. The participation of other types was less than $10 \%$, additionally the unidentified spores accounted about $15 \%$ of the whole list.

In the 6-year cycle, the percentage of amerospores slightly varied and ranged between 0.5 and $1.2 \%$. The lowest participation was noted in 2006. Both types are fourth in terms of numbers of spores recorded group in the area of study and were present in more than $80 \%$ of the samples.

In the Szczecin area, the behavior of amerospores concentration was rather sporadic although a clear increase was observed at the end of the year (September, October and November) (Fig. 1). In order to normalize the date, the log-transformed amerospores concentration was used. Maximum annual concentrations were recorded in 2007, and a maximum value of 189 spore $/ \mathrm{m}^{3}$ measured on 24th October 2008. In 2006 and 2009, the spore seasons were clearly shorter than in other years and the maximum number of spores was the lowest. In both years, the date of occurrence of maximum spore's number was noted at the earliest in comparison to the rest of years studied. The time difference compared to other years ranged from three to 7 weeks (Table 1).

High values of daily concentration of amerospores occurred during the afternoon, from 17.00 to $19.00 \mathrm{~h}$, and late at night, between 04.00 and $06.00 \mathrm{~h}$. In 2005 and 2007, the late-night maximum was delayed about one or $2 \mathrm{~h}$ : 05.00-07.00 and 06.00-08.00, respectively (Fig. 2).

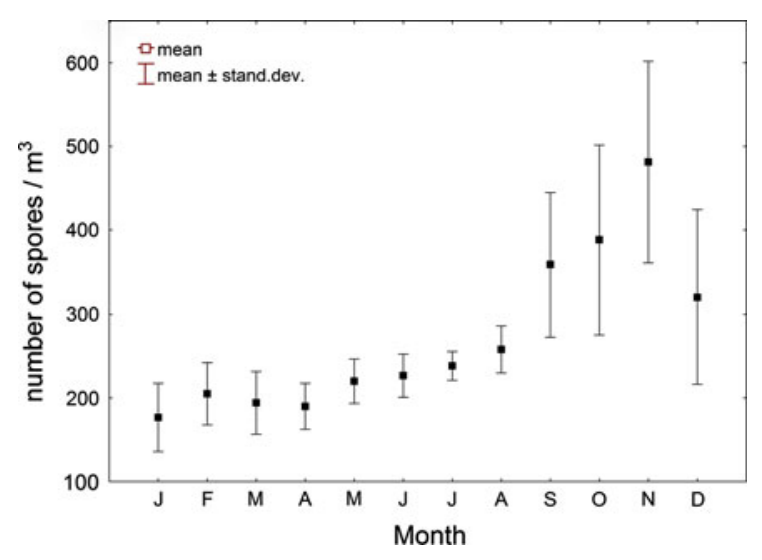

Fig. 1 The frequency of the amerospores in the air from 2004 to 2009 (mean values)
Table 1 Results of aerobiological study of amerospores count- $\log (x)$ values

\begin{tabular}{lllllll}
\hline $\begin{array}{l}\text { Group } \\
\text { of spores }\end{array}$ & 2004 & 2005 & 2006 & 2007 & 2008 & 2009 \\
\hline \multicolumn{2}{l}{ Amerospores } & & & & & \\
Tn & 3.555 & 3.757 & 2.345 & 3.768 & 3.222 & 2.897 \\
Max & 168 & 179 & 142 & 188 & 189 & 122 \\
Date & 2-Nov & 5-Oct & 31-Aug & 25-Sep & 24-Oct & 8-Sep \\
\hline
\end{tabular}

Tn total number of amerospores collected in the spore season established by the $90 \%$ method

Max maximum number of spores $/ \mathrm{m}^{3}$

Date date when the maximum number of spores was noted

Spearman's rank correlations (daily concentration) were calculated for the spore season data set (Table 2). As for the original data set, directly proportional and highly significant dependencies between the amersopores concentration and meteorological factors were observed in the case of dew point temperature. For daily values of dew point temperature, the coefficients were positive, significant for $p=0.001$ and ranged from 0.342 to 0.213 at the same day and 3 days lag. Quite high positive correlation was observed for the relative humidity recorded on the same day or 3 days lag for $p=0.05$ and 0.001 and for average wind speed with each of the three $p$-values. No significant correlation was observed between minimum, maximum and average temperature, precipitation, and maximum wind speed and the spore concentration.

The hourly spore concentration analysis of Spearman's rank correlations (Table 3) show that relative humidity the most strongly and significantly influenced concentration of amerospores. The coefficient was positive, significant for $p=0.001$ and quite high. The weaker but still statistically significant correlation occurred with dew point temperature, wind speed for $p=0.05$ and 0.01 , respectively. Negative correlations were observed with hour, and between rain and air temperature no correlation was noted.

\section{Discussion}

There had not been earlier studies on concentrations of fungal spores in the air from the vicinity of Szczecin. In Poland, last and current studies on the 
Fig. 2 Average diurnal amerospores variations in Szczecin

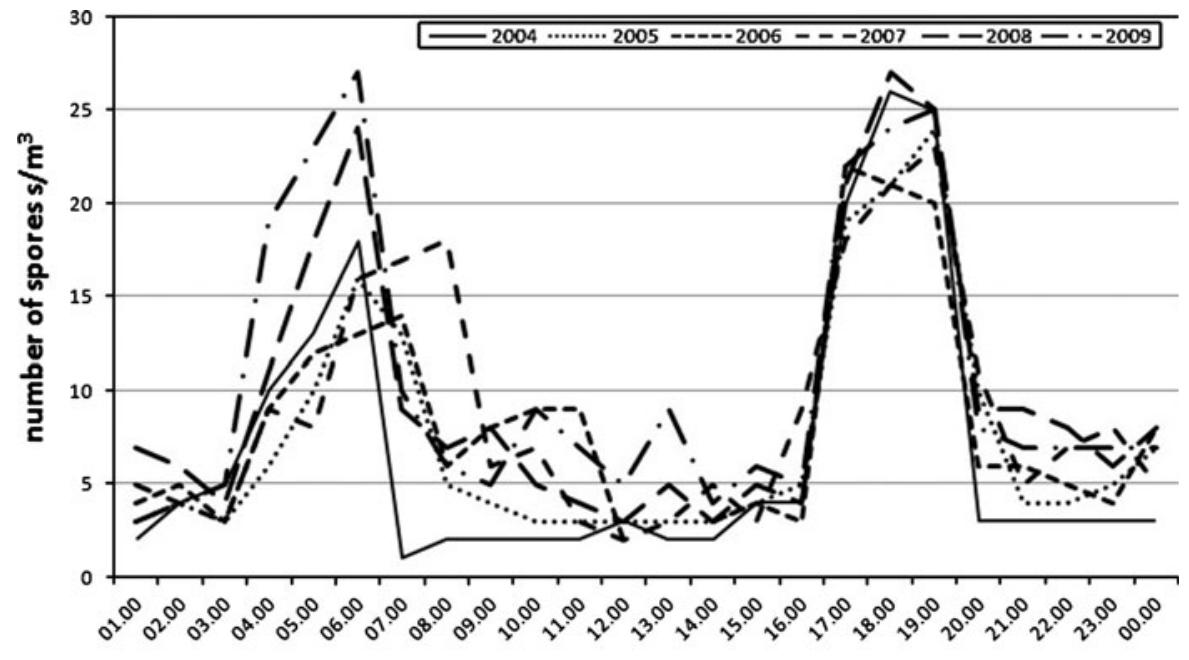

Time of the day

Table 2 Spearman's rank correlation coefficients between amerospores concentration and meteorological variables during spore seasons

\begin{tabular}{lcccc}
\hline Variable & Same day & Lag 1 & Lag 2 & Lag 3 \\
\hline Average temperature & 0.017 & 0.045 & 0.054 & 0.011 \\
Maximum temperature & 0.012 & 0.001 & 0.011 & 0.036 \\
Minimum temperature & 0.015 & 0.059 & 0.023 & 0.036 \\
Dew point temperature & $0.342^{* * *}$ & $0.310^{* * *}$ & $0.251^{* * *}$ & $0.213^{* * *}$ \\
Relative humidity & $0.258^{* * *}$ & $0.281^{* * *}$ & $0.205^{*}$ & $0.153^{* * *}$ \\
Average wind speed & $0.299^{* *}$ & $0.156^{* *}$ & $0.135^{* *}$ & $0.163^{*}$ \\
Maximum wind speed & 0.019 & $-0.106^{*}$ & -0.092 & -0.030 \\
Precipitation & -0.066 & -0.017 & 0.070 & 0.073 \\
\hline
\end{tabular}

$* p<0.05 ; * * p<0.01 ; * * * p<0.001$

Table 3 Spearman's rank correlation coefficients between amerospores concentration, meteorological variables and time of the day

\begin{tabular}{lc}
\hline Variable & Amerospores \\
\hline Hour (time of the day) & $-0.248^{*}$ \\
Air temperature & 0.043 \\
Dew point temperature & $0.239^{*}$ \\
Relative humidity & $0.757^{* * *}$ \\
Wind speed & $0.290^{* *}$ \\
Rain & -0.172 \\
\hline
\end{tabular}

$* p<0.05 ; * * p<0.01 ; * * * p<0.001$

concentration of spores of Aspergillus/Penicillium in the air were conducted only in Cracow (MędrelaKuder 1991, 2003) and in Upper Silesia (Pastuszka et al. 2000); these studies, however, concerned mainly an indoor concentration of spores. Moreover, the outdoor test was conducted by other methods thus comparing the results would not give reliable results. Previous studies regarding the Penicillium had been conducted by Zaleski (1927) in forest soils of Białowieża, in the north-east part of the country. He described 35 new species of this genus. Also Aleksandrowicz et al. (1970) and Aleksandrowicz and Smyk (1973) gave early evidence of the role of mycotoxins in indoor air that concerned the two species: Aspergillus flavus and Penicillium meleagrinum.

The dynamics of aeroallergens in the air is complicated, attributable to many different biological and climatic conditions as: weather and local biological sources. Long-term monitoring and appropriate statistical methods are valuable to explore the 
interrelationships among meteorological parameters on ambient aeroallergens. This 6-year study examined the relationships between amerospores numbers and weather parameters using Spearman rank correlation.

Authors did not found any research results about amerospores in the available aerobiological literature probably because of methodological limitations. But since Aspergillus and Penicillium are the most numerous taxa in this group, we compared our results with the effects of other research on these two types. Based on our previous investigations, we believe that our considerations are sufficient in this type of analysis.

The amerospores were one of the most frequently and existed in the biggest number listed types of spores in the air. The similar reports were obtained from the other parts of the world (Ho et al. 2005; Larsen 1981; Larsen and Gravesen 1991; O'Gorman and Fuller 2008; Oliveira et al. 2009a, b; Padmanabhan and Nayar 2004). Its spore concentration was rather constant throughout the study years, with a slight increase in the late summer and autumn. The same results occurred in Portugal (Oliveira et al. 2009a, b), in India (Padmanabhan and Nayar 2004), in the United Kingdom (Millington and Corden 2005) and in Spain (Guinea et al. 2006; Infante et al. 1995). This was probably due to an abundance of decaying plant material after the trees shed their leaves in the autumn. The large quantities of potential growth material could be one reason for high levels of mold spores in that time of year. Furthermore, the average relative humidity during this period in Szczecin is high about $80 \%$ which, together with temperature above $20^{\circ} \mathrm{C}$, promotes the production and release of spores. The different situation was noted in Ireland by O'Gorman and Fuller (2008) but counted separately for both types of spores. In Dublin, concentrations of Aspergillus peaked in March, June, August, October and November and concentrations of Penicillium did not show much seasonal variation, remaining relatively constant throughout the year. Only from June, its concentrations rose to a significantly higher level. Adhikari et al. (2006) found the highest concentration of Aspergillus/Penicillium during the summer (JuneAugust). In Denmark, the concentrations of Aspergillus/Penicillium seemed to be independent of seasonal changes (Larsen 1981; Larsen and Gravesen 1991), and in Finland a maximum of Penicillium was found in July and minimum in December (Ahlström and Käärik 1977). Rosas et al. (1993) reported Penicillium spore concentration in a tropical region as constant between the dry and rainy seasons and deemed not to be of consequence as aeroallergens there. The same authors in Mexico City noted highest Aspergillus concentration in October (Rosas et al. 1990). Aspergillus concentrations also increased substantially in March and August; matching peaks have been reported by Ebner et al. (1989) for the Austrian Alps. Interesting results were noted in the countries of the Middle East: Jordan and Qatar. In two different places in Jordan (Zarqa area and Amman), an aerobiological monitoring was conducted. The Aspergillus/Penicillium peaks were noted in September and January and March, respectively (Abu-Dieyeh et al. 2010; Shaheen 1992). In Doha, Qatar, the peaks of amerospores were noted in July and August for Penicillium and in July and December for Aspergillus (Al-Subai 2002).

In late summer and autumn, the spore peaks may be explained by the beginning process of seasonal decay of vegetable matter (Larsen 1981). The low spore frequency in the winter months is probably due to the snow cover, but the spore frequencies start decreasing before snowfall when the temperature falls below zero, preventing sporulation. In Szczecin, the high level of spores in the November may be caused by relatively high temperatures (above zero) and humidity. During last years, the snow cover in Szczecin was noted only for several days in January and February.

Amerospore hourly concentrations were high during late afternoon, night and early morning. The similar results were noted by Oliveira et al. (2009a, b) in Portugal where concentrations of Aspergillus/ Penicillium significantly raised during afternoon and night. In Taiwan, the number of spores peaks around midnight (Ho et al. 2005). In Dublin, Aspergillus spores did not fluctuate significantly during the day and Penicillium concentrations were at their highest in the mornings (O'Gorman and Fuller 2008). The different results were obtained from Northeast Oklahoma by Gillum and Levetin (2008), where the highest hourly spore concentration of Aspergillus/ Penicillium occurred at $10.00 \mathrm{~h}$, then decreased after $14.00 \mathrm{~h}$, and remained lower for the rest of the day. Likewise, in the United Kingdom, on peak days, the highest amerospore concentrations usually occurred 
toward the middle of the day, around $11.00 \mathrm{~h}$ (Millington and Corden 2005).

The most important meteorological factor affecting airborne spore concentrations in Szczecin were dew point temperature and relative humidity. Both parameters were positively correlated with airborne amerospores count in this study. The same results were noted by Quintero et al. (2010) in Puerto Rico (one of the Greater Antilles islands). They also noted positive correlation with the air temperature. Relatively high and similar correlation coefficients for both parameters can be explained by close relationships between dew point temperature and relative humidity of air. The dew point is the temperature to which the air must be cooled before it becomes saturated and water must condense out. Most often we meet humidity as "relative humidity" given as a percent-meaning the higher the percent, the closer the temperature and dew point are. The third and the final positively correlated factor was an average wind speed, but in comparison with the dew point temperature and relative humidity, the statistical coefficient was lower. The negative correlation for wind speed was noted by Quintero et al. (2010), and the coefficient for precipitation was insignificant similarly to the results of this research.

Water is one of the essential environmental factors determining fungal survival and growth. Relative humidity is measure associated with water-availability outdoors. Spores require sufficient moisture for dispersal as humidity increases. Quintero et al. (2010) wrote that in the subsequent hours, in which humidity accumulated in the environment, the concentration of fungal aerosols also increased, with significant differences in the concentrations of spores during and after the rain events. They also noted four times higher concentration of Aspergillus and Penicillium during rainy season (September-November).

There is no clear picture of effects of relative humidity on Aspergillius and Penicillium conidia, and this is reflected in the inconsistent results seen in the literature. Rosas et al. (1993) found slight negative correlation between airborne Penicillium conidia and relative humidity, as did Li and Kendrick (1995) and Ho et al. (2005). In agreement with this the Irish study, Wu et al. (2007) reported a positive relationship between both airborne Penicillium and Aspergillus spore counts and relative humidity. In Puerto Rico, the higher concentrations of fungal spores (including Aspergillus and Penicillium) were observed at midnight and early morning hours (Quintero et al. 2010). They supposed that this intradiurnal rhythm, in which the highest abundance of spores present between the midnight and early morning period, suggests an active release mechanism induced by the high dew point and increased humidity prevalent at dawn.

Average wind speed was shown to be less important factor than relative humidity and dew point temperature for Aspergillus/Penicillium, but it directly promotes the release of the dry conidia of these genera ( $\mathrm{Li}$ and Kendrick 1995). The similar results were noted by O'Gorman and Fuller (2008) in Dublin. Spore function as both reproductive and dispersal units of fungi, with the majority of spore types adapted for airborne dispersal. In still air, spores would fall to the ground in response to gravity at a rate (based on Stokes' law) that in proportional to the square of the spore radius for a spherical particle (Gregory 1973). Aerodynamic behavior is also influenced by the shape and surface characteristic of spores. Spore ornamentation and non-spherical shape increase surface drag. This effectively decreases aerodynamic size and delays deposition. Aerodynamic behavior is also altered by spore aggregation. Spores of both taxa Aspergillus and Penicillium and other genera belonging to the amerospores' group have spherical or round and rather smooth conidia (Gravesen 1979). They frequently occur as aggregates, either as irregular masses or more as chains, in the atmosphere. Aggregation increases particle size, which tends to increase the rate of fall.

The air temperature as one of the most important meteorological factors affecting the level of concentration of many types of mold spores in the air for both types showed no statistically significant correlation. These results agree with the effects reported by the other authors (Ho et al. 2005; Li and Kendrick 1995; O'Gorman and Fuller 2008). In contrast to those observations, the Adhikari et al. (2006) found positive relationships between Aspergillus/Penicillium and air temperature.

Hasnain (1993) and Oliveira et al. (2009a, b) did not find any correlation between these type of spores and meteorological parameters. Both authors used the same statistical method-Spearman rank correlation coefficient. Oliveira et al. (2009a, b) conclude that this lack of association between spore occurrence and 
the analyzed meteorological data could be explained by the sporadic behavior of these spores.

Very similar results were obtained from hourly values of meteorological parameters and the concentration of amerospores in the air. The same parameters also showed statistically significant positive correlation with amerospores count, but this relationship was weaker than the relation in the data collected diurnally. This can be explained by the less intense fluctuations in the number of spores in the hourly cycle than in the diurnal one. Because the correlation for both types of cycle (hourly and diurnal) is very similar, one can conclude that dew point temperature and relative humidity with average wind speed are the most important meteorological factors for behavior of airborne amerospores count.

Penicillium and Aspergillus are both common soil fungi decaying dead plant material outdoors and are produced in response to the temperature and moisture conditions (Burge and Rogers 2000). Nevertheless, relative humidity, dew point temperature and average wind speed were the only measured meteorological parameters significantly associated with this fungal category. Additional environmental factors, such as local agricultural activities, near-by biological sources, wind direction and sunlight, should be considered in the future studies to fully understand the behavior of Aspergillus, Penicillium and other amenospores.

According to the previous studies, one can conclude that there is no one universal method for combining continuous sampling from the air with a reliable determination of all spore types. The volumetric method, based on Burkard or Lanzoni spore trap, is selective and less effective in the case of particles with a diameter below $5 \mu \mathrm{m}$. This could undercut the number of spores in the air which occur abundantly e.g. Aspergillus, Penicillium and some basidiospores.

The "viable" method (cultivation on the medium) using the Andersen impactor enables quite precise identification of spores. Unfortunately, this method is also selective because not all kinds of spore germinate on the same substrate.

Consequently, none of the methods do not provide complete information about the actual concentration of spores in the air. The ideal solution would be to use both methods simultaneously but it is impossible because of the very high costs.
We realize about the imperfections of the volumetric method, but we do believe that it is sufficient for aerobiological and allergological tests.

Open Access This article is distributed under the terms of the Creative Commons Attribution Noncommercial License which permits any noncommercial use, distribution, and reproduction in any medium, provided the original author(s) and source are credited.

\section{References}

Abu-Dieyeh, M. H., Barham, R., Abu-Elteen, K., Al-Rashidi, R., Shaheen, I. (2010). Seasonal variation of fungal spore populations in the atmosphere of Zarqa area, Jordan. Aerobiologia. doi: 10.1007/s10453-010-9162-2.

Adhikari, A., Reponen, T., Grinshpun, S. A., Martuzevicius, D., \& LeMasters, G. (2006). Correlation of ambient inhalable bioaerosols with particulate matter and ozone: A two-year study. Environmental Pollution, 140, 16-28.

Ahlström, K., \& Käärik, A. (1977). A study of airborne fungal spores with the aid of the FOA slit-sampler. Grana, 16, 133-137.

Aleksandrowicz, J., \& Smyk, B. (1973). The association of neoplastic diseases and mycotoxins in the environment. Texas Reports on Biology and Medicine, 31, 715-726.

Aleksandrowicz, J., Smyk, B., Czachor, M., \& Schiffer, Z. (1970). Mycotoxins in a plastic and proliferative blond diseases. Lancet, 1, 43.

Al-Subai, A. A. (2002). Air-borne fungi at Doha, Qatar. Aerobiologia, 18(3-4), 175-183.

Bridge, P. D., Hawksworth, D. L., Kozakiewicz, Z., Onions, A. H. S., Paterson, R. R. M., Sackin, M. J., et al. (1989). A reappraisal of the terverticilliate penicillia using biochemical, physiological, and morphological features. I. Numerical taxonomy. Journal of General Microbiology, 135, 2941-2966.

British Aerobiology Federation. (1995). Airborne pollens and spores. A guide to trapping and counting (1st ed.). Rotherham, UK: Natl Pollen \& Hayfever Bureau.

Burge, H. A., \& Rogers, C. A. (2000). Outdoors allergens. Environmental Health Perspectives, 108, 653-659.

Ebner, M. R., Haselwandter, K., \& Frank, A. (1989). Seasonal fluctuations of airborne fungal allergens. Mycological Research, 92, 170-176.

Frisvad, J. C., Filtenborg, O., Lund, F., \& Samson, R. A. (2000). In R. A. Samson \& J. I. Pitt (Eds.), Integration of modern taxonomic methods for penicillium and aspergillus classification (pp. 265-283). The Netherlands: Harwood Academic.

Gaweł, J., Halota, A., Pisiewicz, K., Kurzawa, R., Redliński, J., \& Doniec, Z. (1996). Allergenic air borne sporomorphs calendar for Rabka (southern Poland), 1991-1995. Annals of Agricultural and Environmental Medicine, 3, 87-98.

Gillum, S., \& Levetin, E. (2008). The air spora close to a compost facility in Northeast Oklahoma: Part I-spore tramp sampling. Aerobiologia, 24, 3-12.

Gravesen, S. (1979). Fungi as a cause of allergic disease. Allergy, 34, 135-154. 
Gregory, P. H. (1973). The microbiology of the atmosphere. Aylesburg: Hill.

Guinea, J., Peláez, T., Alcalá, L., \& Bouza, E. (2006). Outdoor environmental levels of Aspergillus spp. conidia over a wide geographical area. Medical Mycology, 44, 349-356.

Hasnain, S. M. (1993). Influence of meteorological factors on the air spora. Grana, 32, 184-188.

Ho, H.-M., Rao, C. Y., Hsu, H.-H., Chiu, Y.-H., Liu, Ch.-M., \& Chao, J. H. (2005). Characteristic and determinants of ambient fungal spores in Hualien, Taiwan. Atmospheric Environment, 39, 5839-5850.

Infante, F., Angulo, J., Dominquez Vilches, E., Galán, C., Mediavilla, A., \& Trujillo, D. (1995). Presence of Aspergillus Mich. ex Fr. in several different biotops in Córdoba (Spain). Aerobiologia, 11, 137-143.

Kasprzyk, I., Rzepowska, B., \& Wasylów, M. (2004). Fungal spores in the atmosphere of Rzeszów (South-East Poland). Annals of Agricultural and Environmental Medicine, 11, 285-289.

Konopińska, A. (2004). Monitoring of Alternaria Ness and Cladosporium link airborne spores in Lublin (Poland) in 2002. Annals of Agricultural and Environmental Medicine, 11, 347-349.

Larsen, L. (1981). A three-year-survey of microfungi in the air of Copenhagen 1977-79. Allergy, 36, 15-22.

Larsen, L., \& Gravesen, S. (1991). Seasonal variation of outdoor airborne viable microfungi in Copenhagen, Denmark. Grana, 30, 467-471.

Li, D.-W., \& Kendrick, B. (1995). A year-round study on functional relationships of airborne fungi with meteorological factors. International Journal of Biometeorology, 39, 74-80.

Mędrela-Kuder, E. (1991). Mikroflora powietrza i jej zanieczyszczenie dla kształtowania warunków higienicznych niektórych obiektów i pomieszczeń szkoleniowych AWF Kraków-Czyżyny. Zesz Nauk AWF, 66, 43-79.

Mędrela-Kuder, E. (2003). Seasonal variations in the occurence of culturable air borne fungi in outdoor and indoor air n Craców. International Biodeterioration \& Biodegradation, 52, 203-205.

Millington, W., \& Corden, J. (2005). Long terms trends in outdoor Aspergillus/Penicillium spore concentration in Derby, UK from 1970 to 2003 and a comparative study in 1994 and 1996 with indoor air of two local houses. Aerobiologia, 21, 105-113.

Myszkowska, D., Stępalska, D., Obtułowicz, K., \& Porębski, G. (2002). The relationship between airborne pollen and fungal spore concentrations and seasonal pollen allergy symptoms in Cracow in 1997-1999. Aerobiologia, 18, 153-161.

O'Gorman, C. M., \& Fuller, H. T. (2008). Prevalence of culturable airborne spores of selected allergenic and pathogenic fungi in outdoor air. Atmospheric Environment, 42, 4355-4368.

Oliveira, M., Ribeiro, H., Delgado, J. L., \& Abreu, I. (2009a). The effects of meteorological factors on airborne fungal spore concentration in two areas differing in urbanisation level. International Journal of Biometeorology, 53, 61-73.

Oliveira, M., Ribeiro, H., Delgado, J. L., \& Abreu, I. (2009b). Seasonal and intradiurnal variation of allergenic fungal spores in urban and rural areas of the North of Portugal. Aerobiologia. doi: 10.1007/s10453-009-9112-z.

Onions, A. H. S., Bridge, P., \& Paterson, R. R. M. (1984). Problem and prospects for the taxonomy of Penicillium. Microbiological sciences, 1, 185-189.

Padmanabhan, S. J., \& Nayar, T. S. (2004). Airborne fungal spores in a sawmill environment in Palakkad district, Kerala, India. Aerobiologia, 20, 75-81.

Pastuszka, J. S., Kyaw Tha Paw, U., Lis, D. O., Wlazło, A., \& Ulfig, K. (2000). Bacterial and fungal aerosol in indoor environment in Upper Silesia, Poland. Atmospheric Environment, 34, 3833-3842.

Paterson, R. R. M., Bridge, P. D., Crosswaite, M. J., \& Hawksworth, D. L. (1989). A reappraisal of the terverticilliate penicillia using biochemical, physiological, and morphological features. III. An evaluation of pectinases and amylase isozymes for species characterization. Journal of General Microbiology, 135, 2979-2991.

Paterson, R. R. M., Kozakiewicz, Z., Locke, T., Brayford, D., \& Jones, S. C. B. (2003). Novel use of the isoepoxydon dehydrogenase gene probe of the patulin metabolic pathway and chromatography to test penicillia isolated from apple production systems for the potential to contaminate apple juice with patulin. Food microbiology, 20, 359-364.

Paterson, R. R. M., Venâncio, A., \& Lima, N. (2004). Solutions to Penicillium taxonomy crucial to mycotoxin research and health. Research in Microbiology, 155, 507-513.

Peterson, S. W. (2000). In R. A. Samson \& J. I. Pitt (Eds.), Integration of modern taxonomic methods for penicillium and aspergillus classification (pp. 163-178). The Netherlands: Hardwood academic.

Quintero, E., Rivera-Mariani, F., \& Bolaños-Rosero, B. (2010). Analysis of environmental factors and their effects on fungal spores in the atmosphere of a tropical urban area (San juan, Puerto Rico). Aerobiologia, 26, 113-124.

Rodriquez-Rajo, F., Iglesias, I., \& Jato, V. (2005). Variation assessment of airborne Alternaria and Cladosporium at different bioclimatical conditions. Mycological Research, 109, 497-507.

Rosas, I., Calderon, C., Ulloa, M., \& Lacey, J. (1993). Abundance of airborne penicillium CFU in relation to urbanization in Mexico city. Applied and Environmental Microbiology, 58, 2648-2652.

Rosas, I., Escamilla, B., Calderon, C., \& Mosiño, P. (1990). The daily variations of airborne fungal spores in Mexico city. Aerobiologia, 6, 153-158.

Samson, R. A., \& Pitt, J. I. (Eds). (1990). Modern concepts in Penicillium and Aspergillus classification. New York: Plenum Press.

Shaheen, I. (1992). Aeromycology of Amman area, Jordan. Grana, 31, 223-228.

Stępalska, D., Harmata, K., Kasprzyk, I., Myszkowska, D., \& Stach, A. (1999). Occurrence of airborne Cladosporium and Alternaria spores in southern and central Poland in 1995-1996. Aerobiologia, 15, 39-47.

Stępalska, D., \& Wołek, J. (2005). Variation in fungal spore concentration of selected taxa associated to weather condition in Cracow, Poland, in 1997. Aerobiologia, 21, 43-52.

Weiss, A. (1962). Über das Pilzsporenvorkommen in der Luft in Kraków und Bad Rabka. Allerg Asthma, 8, 298-303. 
Wu, Y. H., Chan, C. C., Rao, C. Y., Lee, C. T., Hsu, H. H., Chiu, Y. H., et al. (2007). Characteristics, determinants, and spatial variations of ambient fungal levels in the subtropical Taipei metropolis. Atmospheric Environment, 41, 2500-2509.
Zaleski, K. (1927). Über die in Polen gefundenen Arten der Gruppe Penicillium Link. I, II, III. Bulletin International de l'Academie Polonaise des Sciences et des Lettres, Cracovie, B, 417-563. 